\title{
Reflexiones acerca del paisaje y el problema del conocimiento
}

Reflections about landscape and knowledge problem

\author{
GABRIELA RAPOSO QUINTANA ${ }^{1}$ \\ ${ }^{1}$ Universidad Academia de Humanismo Cristiano, Santiago, Chile. \\ e-mail: gabriela@raposo.cl
}

\section{RESUMEN}

Se reflexiona en torno a la idea de paisaje, tanto a nivel de concepto (paisaje como idea) como en su consideración de realidad (paisaje como cosa). Se hace dialogar a algunos autores, que desde el problema del conocimiento, abordan temáticas tales como la imagen, la belleza o la subjetividad, en vías de desarrollar un argumento sobre la comprensión de la noción de paisaje.

Palabras clave: Paisaje, imagen, percepción.

\section{SUMMARY}

It is thought over concerning the idea of landscape, so much to level of concept (landscape like idea) as in his consideration of reality (landscape like thing). It proposes to make compose in a dialogue some authors, who from the problem of the knowledge, approach such subject matters as the image, the beauty or the subjectivity, in routes to develop an argument on the comprehension of the notion of landscape.

Key-words: Landscape, image, perception. 
INTRODUCCIÓN

El paisaje es una de las dimensiones que ha sido objeto recurrente de investigación en los últimos años y en los más variados campos disciplinares. Esta dimensión ha sido estudiada como un objeto en sí (paisaje como cosa), es decir, la indagación acerca de un determinado paisaje (el paisaje urbano o el paisaje santiaguino, por ejemplo), pero también desde el punto de vista teórico (paisaje como idea), procurando entender qué es el paisaje, cómo se forma, cómo se construye y cómo se concibe en tanto percepción, interpretación y representación, principalmente en un afán por tratar de definirlo o delimitarlo en términos conceptuales. $\mathrm{Al}$ estudiar un determinado paisaje, más allá de contrastar visiones metodológicas respecto de cómo comprender la realidad que él involucra, lo que se cuestiona es si es posible por medio de su descripción, dar cuenta de una realidad aparentemente objetiva, es decir, aquella que hace que un determinado paisaje sea aquel y no otro. Estas miradas son las mismas que desde el punto de vista teórico, generan diálogos que nacen desde las interpretaciones y visiones de mundo de diversas disciplinas, ya sea estén vinculadas a la comprensión de los procesos naturales, históricos, económicos y sociales que se yuxtaponen y ayudan a construir el paisaje como objeto, al mismo tiempo que lo constituyen y lo delimitan desde el punto de vista conceptual.
En este ensayo se reflexiona acerca de la noción de paisaje, desde el punto de vista de su comprensión y de su conceptualización como fenómeno presente en la vida cotidiana de los grupos humanos, relacionándolo al problema del conocimiento. Las reflexiones que conforman el documento que aquí se presenta, se desarrollan a partir de la exposición de algunos aspectos que versan sobre la problemática del conocimiento, principalmente desde fragmentos de las lecturas de Dantó, Aristóteles, Flores, Husserl y Gadamer. Asimismo se incorpora a la reflexión textos de autores que, desde el ámbito académico de la arquitectura, la arquitectura del paisaje y el urbanismo, procuran dotar a la noción de paisaje de una definición formal.

\section{UN ALCANCE PREVIO SOBRE LA NO- CIÓN DE PAISAJE}

Es diversa la literatura que ha procurado explicar la noción de paisaje, ya sea tanto desde el ámbito de las ciencias como de las artes. Algunos autores, como Appleton (1996) y Spirn (1998), coinciden en que la gran diversidad disciplinaria que comprende el estudio del paisaje, (ver revisiones de Maderuelo 2005 y 2006 y de Nogué (2007 y 2008), hace que no sea posible tener una visión completa sobre esta noción, siendo particularmente difícil definirlo desde el punto de vista científico, ya que ello implicaría conocer todos los elementos que contiene el 
concepto paisaje y que de hecho lo nutren y modifican. Sin embargo, sí existe consenso en que el paisaje debería ser entendido como la relación entre un espacio, en cuanto estructura física tangible y su relación con el ser humano, quien a través de los sentidos (percepción), de la interpretación de éstos y de la representación (textual, visual y significante), sería capaz de comprenderlo. Si bien en los ultimos años se ha reconocido el rol de olores, sonidos y texturas en la configuración del paisaje, la visión sigue siendo el sentido más reconocido por varios autores (ver $\mathrm{Du}$ rán 2007).

Otro acercamiento es el propuesto por Maderuelo (2005), quien procura entender el concepto paisaje desde sus raíces etimológicas, que son varias. En inglés, alemán y holandés se relacionan con nociones territoriales, que a través de los siglos, han desplazado sus significaciones originales a cuestiones relacionadas al aspecto o características de un territorio. Dentro del contexto occidental europeo, el autor señala que el italiano fue el primer idioma en el que se generaron las terminologías para nombrar tanto el territorio como las vistas de él. La raíz latina de éstas se encontraría en el término pago como expresión de la idea de lugar, el cual con el tiempo habría dado paso a la palabra país. Fueron los pagos y países, representados por la pintura en los cuadros, los que dieron cuerpo a la noción de paisaje (como pedazos de países), vinculados también a las nociones de naturaleza, belleza $\mathrm{y}$ de valoraciốn estética de los paisajes a través de la pintura. Visión similar es la presentada por Alpers (1987), quien a partir del desarrollo del arte pictórico holandés, explica la evolución que habría tenido la forma de conceptualizar el paisaje, nuevamente en asociación con su valoración estética.

\section{Para Tesser (2000), el paisaje} contiene cuatro dimensiones: a) la estética: se evidenciaría en la pintura y la literatura, b) la ecológica: estaría presente en la relación de los elementos del mundo natural, c) la cultural: correspondería al escenario de las actividades humanas, y d) la interpretativa: correspondería a los elementos que nos es posible percibir. Para los autores revisados previamente, estas dimensiones se dan en su conjunto y serían aprehendidas gracias a la percepción, interpretación y la representación, independientemente del fin que conlleve la comprensión de un paisaje. En esta misma línea, para Maderuelo (2005) el paisaje se circunscribiría a la relación subjetiva entre el hombre y aquello que éste puede ver. Más aún, se refiere al paisaje como a un concepto inventado o a una construcción cultural. Shama (1995) profundiza esta idea, definiendo al paisaje como una compleja red de observaciones, mitos, memorias y significados, otorgándole a la experiencia un sitial importante en la comprensión de este concepto (ver también Tuan 1983). De esta manera el paisaje, más allá de sus alcances etimológicos; ha sido explicado a partir de su vinculación con los sentidos, el arte y: la na- 
turaleza, constituyéndose además, en tanto lugar, en el escenario en el cual se desarrollaría la vida.

\section{REFLEXIONES ACERCA DEL PAISAJE}

\section{LA BELLEZA DEL PAISAJE}

Un acercamiento al paisaje sugiere que la comprensión de esta noción, al menos en el mundo occidental, sólo pudo materializarse a partir del desarrollo del arte pictórico. El paisaje para existir, debía reconocerse como tal, no sólo en términos contemplativos, sino que también de admiración y valoración estética. Maderuelo (2005) señala que el término paisaje surgió en el seno del arte de la pintura, por lo cual existiría una relación a través de la mirada. En este caso existiría la interpretación de lo que se observa y la representación del paisaje hecho imagen, por medio de la pintura, para luego dar paso a la interpretación de la imagen del paisaje, en tanto "obra de arte", por medio de quien la observa. Esta forma de comprender el paisaje, en tanto representación e interpretación artística, nos lleva a acercarnos a la idea de paisaje entendido por medio de la expresión y conocimiento artístico. Sin embargo, la idea de goce y placer intelectual (así lo reconocen los autores antes mencionados) entendido como la aprehensión de lo bello en su conjunto por aquello que constituye el paisaje, nos plantea la po- sibilidad de la crítica a la idea del arte como lo bello y en este caso, al paisaje representado e interpretado -por medio del arte-como lo bello.

El paisaje como expresión artística y representación de la belleza, trascendería a la pieza "obra de arte" y alcanzaría a la realidad que fue representada, ya que la obra que representa procura evidenciar la belleza de lo que se observó. Sin embargo, Dantó (2005) cuestiona la noción de arte y belleza, resituándolas a partir de los cambios en los tiempos actuales: el cuestionamiento sobre qué es arte y la producción de la obra que omite a la belleza, que trata de eliminarla, pero que el autor propone reintegrar. Surge luego la necesidad de entender cómo son los cambios respecto de aquello que se observa y qué puede ser admirado y representado por medio de una imagen.

En este marco del paisaje como "obra de arte", el concepto se amplió. La libertad que dio la posibilidad de representar el paisaje con otros medios visuales, como la fotografía, así como también la libertad de extender aquello por lo que se podía sentir goce y placer intelectual, supusieron en este contexto un aumento de aquello susceptible de ser entendido como paisaje. En este sentido, las representaciones del paisaje del arte pictórico campestre, resultan ser tan posibles como las representaciones de paisajes del arte fotográfico de los desnudos de Tunic en el Parque Forestal de Santiago de Chile (a propósito del fotógrafo Spencer Tunick, en su gira "Desnudo a la deriva", realizada en 
diversas ciudades del mundo). Dantó propone dotar al concepto de belleza de un contexto más modesto y con menor autoridad moral, de tal manera que puedan integrarse otras expresiones quizá menos tradicionales. La valoración de la obra que representa al paisaje, más allá del contenido que como imagen y comprensión del paisaje puede aportar, implica también una valoración de las técnicas y tecnologías que sirvieron de apoyo a su creación. Sin embargo, lo que es de interés en esta reflexión, es el impacto que tiene la valoración del arte y la incorporación o exclusión de la belleza, tanto en la conceptualización, como la comprensión y evolución de la noción de paisaje. En este sentido, el contenido subjetivo que Dantó reconoce en la valoración de la belleza resulta ser válido también en la valoración del paisaje y, en el caso del arte, en la representación del paisaje, tanto como en su conceptualización.

\section{DE LA PERCEPCIÓN A LA IMAGEN DEL PAISAJE}

Existe consenso académico al señalar que el paisaje se constituiría a partir de una relación subjetiva entre el hombre y aquello que éste percibe por medio de los sentidos. Luego, el paisaje implicaría oler, tocar, oír, ver y gustar lo que está en el exterior. Cuando hablamos de sentidos, en vinculación al paisaje, hablamos entomces de todo lo que podemos captar o percibir de ese exterior, gracias a que tenemos ór- ganos sensoriales. Sobre esto, Aristóteles plantea que estos sentidos pueden percibir, en tanto y dado que existe la facultad sensitiva y un objeto portador de cualidades sensibles. La cualidad sensible en potencia (aquello que distingue al objeto) pasa al acto, en tanto que la facultad sensitiva (aquella que poseen los órganos sensoriales) pasa también de la potencia al acto, es entonces cuando hablamos de percepción. Es decir, que el ojo perciba colores o que el oído perciba sonidos. Tomando lo anterior se podría señalar que el paisaje (cosa) podría existir, dado que estaría conformado de objetos con cualidades sensibles, los cuales son posibles de ser percibidos por un observador portador de la facultad sensitiva. Junto con ello y retomando a Aristóteles, el autor señala que la cualidad sensible permanece (en el órgano) a nivel de sensaciones e imágenes, sin necesidad de la presencia material del objeto. De manera similar, el paisaje en tanto memoria, permanecería en el observador.

Para Aristóteles, debe existir alguna facultad, además de aquella dada por los sentidos, que percibe las diferencias en las cualidades sensibles, por ejemplo, en el color o en el sonido. Expone que esa facultad es capaz de inteligir, dado que es capaz de discernir entre cualidades sensibles. Esta actividad cognitiva se da, gracias a la facultad intelectiva del alma y se realizaría sólo dado que existe la facultad sensitiva. Lo que es percibido visualmente origina una imagen sobre la cual el intelecto capta la forma -entendida 
como la esencia del objeto percibido-y razona. En otras palabras, el intelecto requiere de las imágenes que surgen de la percepción para inteligir (i.e. del latín, inte (hacia dentro), legere (leer), o leer hacia adentro. "Inteligir" es la actividad del ser humano que lo vuelca hacia dentro de su ser para buscar la comprensión de sí mismo y del mundo que lo rodea). En este sentido, el paisaje, si bien se refiere a aquello que se percibe de la realidad, sólo puede ser percibido como realidad una vez que es inteligido. Igualmente ocurre cuando el paisaje es representado, ya sea en imágenes visuales o en la literatura. Se percibe "el exterior" y se crea la imagen como condición necesaria para el dominio intelectual. Una vez comprendida su esencia, es posible llegar a construir el concepto de ese exterior y entonces se crea el paisaje (en su singularidad como cosa). Este mismo puede representarse posteriormente por medio de una imagen pictórica, si bien ya no sería el paisaje sino su representación. Junto con ello, el conocimiento del paisaje en tanto forma, puede aportar a la conceptualización de la noción de paisaje (no en sentido particular, sino que como concepto universal).

Sin embargo, por parte de los autores que definen paisaje, existe el reconocimiento que la relación que media entre objeto y hombre, por medio de la percepción, es una relación subjetiva. En otras palabras, la captación de las cualidades sensibles por los sentidos, no asegura que la esencia del objeto (cosa) pueda ser captada de modo objetivo (igual a la cosa), ya que la formación de la imagen también estaría impregnada de las experiencias del hombre. En este sentido, la argumentación de Aristóteles tiende a comprender lo inteligido como objetivo, dado que la construcción de la forma en cuanto esencia del objeto, es objetiva. Distintamente, la noción de paisaje plantea que lo percibido es siempre una interpretación de la realidad, ya que la forma en que pueda construirse el paisaje como cosa (entendida como esencia del objeto), se hace a partir de la comprensión (intelectual) subjetiva de lo percibido. De esta manera, lo percibido por dos individuos no necesariamente implicaría una misma comprensión del exterior, por lo que el resultado serían paisajes distintos. Pese a ello, independientemente del entendimiento del paisaje como objeto, el paisaje (en su singularidad) sí requiere de la captación desde el intelecto, es decir, de la esencia del objeto. El paisaje, en este sentido, reconocería la actividad intelectiva en su formulación.

Al igual que las facultades sensitivas y las cualidades sensibles que pueden darse en acto o en potencia, lo mismo puede ser entendido a partir del objeto. Para Aristóteles el objeto es materia (potencia) y forma (acto) al mismo tiempo y de manera interdependiente. La forma no tiene existencia propia, sino que se realiza sobre "la fuerza que tiene la materia. La materia corresponde a la realidad (potencia). Sin embargo, es el alma quien la asimila (acto), no como realidad sino como 
significación en la medida que se le defina y acote para un determinado fin, cuestión que se suele realizar dentro de los diversos marcos disciplinares que trabajan con el concepto paisaje.

\section{EL PAISAJE DESDE EL SUJETO}

Gadamer (1987) explica que la ciencia siempre ha tenido la pretensión de superar la experiencia subjetiva mediante el conocimiento objetivo, de tal manera que frente al concepto haya sólo univocidad (i.e. una interpretación posible). Sin embargo, cuestiona la noción de verdad que el plano del discurso tendía a objetivar, planteando que la verdad del discurso sería en realidad, la adecuación del discurso a la cosa presente. En este sentido, reconoce en el discurso la cualidad de ser entendido en un contexto, el cual trasciende el enunciado del discurso de verdad y entra en el plano intrasubjetivo. En este plano, más allá del contenido mental, importa también la motivación, supuestos y la pregunta que pretende responder el enunciado. La verdad, en este marco, no es neutral ni atemporal, sino que se genera y se construye a partir de un diálogo e interpelación que trasciende al enunciado, pero que se evidencia a partir de él. El enunciado en este contexto, pertenece al conjunto de una existencia histórica, luego, para comprenderlo, debemos aclarar dónde y cómo se formularon las ideas que lo sustentan, cuál es su motivo y cuál es su sentido.
Respecto de la necesidad de objetivar a nivel de conceptualización del paisaje, como se ha explicado, uno de los mecanismos que garantizarían esta cualidad, sería procurar definir la noción de paisaje a partir de elementos que puedan ser claramente identificados y medidos, situación que suele materializarse en disciplinas tales como la geografía. Sin embargo, la noción de paisaje que aparece en los textos académicos vinculados a la arquitectura y urbanismo, lo entienden como una realidad objetiva. A su vez, la interpretación de este paisaje se reconoce y define como subjetiva ya que parte desde la percepción. En este contexto, la interpretación de lo que es percibido, sería también una forma de interpretar el paisaje, ya que se encontraría vinculada a códigos que aprendemos en el transcurso de nuestra vida, tales como por ejemplo, dotar de valor a un olor o a un color. En otras palabras, se le asignarían valoraciones diversas a los diferentes elementos, que desde el punto de vista conceptual, se conjugarían para constituir el paisaje. Si bien se reconoce la diversidad de interpretaciones posibles gracias a la existencia de esa relación subjetiva, también es claro que existirían ciertos patrones sociales y conductuales dentro de nuestra cultura occidental, que nos llevarían a significados comunes en esta relación, y por tanto, harían posible cierta coherencia entre unas y otras significaciones, gracias a las cuales podríamos entender el paisaje. 
En este sentido, el paisaje se daría como un discurso que surgiría desde el plano intrasubjetivo respecto de la realidad, pero en un diálogo donde tanto la realidad como lo subjetivo, se entiendan sólo bajo un contexto histórico dado. La realidad sería leída como texto, pero esa lectura tendría una orientación que coadyuvaría en la formulación del paisaje, en cuanto concepto. Esa formulación tendría motivaciones diversas, lo que explicaría por ejemplo, el origen de la noción de paisaje desde la pintura o sus diversas definiciones en las diferentes disciplinas. De la misma manera sería posible entender que una misma realidad, pudiese generar variedades de paisajes, hechos, enunciados $\mathrm{y}$ verdades, dependiendo de los grupos humanos que los generen.

\section{CONCLUSIÓN}

La noción de paisaje es tan amplia, que es posible darle cabida en todas las problemáticas presentes en los autores que aquí se han revisado. La relación que éstas tienen con la noción de paisaje permiten cuestionarla, pero también desmembrarla para poder reconstruirla y entenderla. En cierto sentido, para saber de qué está hecha: El paisaje nacido desde la facultad otorgada por los sentidos, pero razonado, inteligido, hecho acto. El paisaje hecho imagen como representación a través de la pintura, valorado y cuestionado estéticamente, trasciende a la pintura, queriendo llegar a la realidad y permitiendo dar cabida a su comprensión como concepto, pero también a su idealización estética. El paisaje percibido y simplificado hecho imagen mental, esquematizado, permite reconocerlo en su singularidad y como noción universal. Dadas las limitaciones en su conceptualización y la posibilidad de definir el paisaje desde una realidad distinta a la de la subjetividad de quien observa, el paisaje es hecho texto, diálogo e interpelación.

Finalmente, sólo queda revisitar algunos aspectos. El paisaje requiere de una realidad, de los sentidos y de la percepción, debe ser inteligido. Se entiende, sin embargo, como un fenómeno construido a partir de la subjetividad de los grupos humanos, por lo que en este sentido, el paisaje podría ser entendido como el resultado de las experiencias individuales y colectivas de estos grupos, que en base a las interpretaciones de sus percepciones, vivencias y memorias, construyen significados atribuidos al paisaje, en cuanto cosa misma o concepto. Desde la fenomenología, sería la conciencia sobre el paisaje la que constituiría sus sentidos y significaciones. Las interpretaciones se vuelven esquema e imagen. Sin embargo, para ser explicado, para que otro distinto pueda leerlo (como texto o discurso), entonces el paisaje es representado, y ya no es paisaje, sino representación. Una definición de paisaje, sin embargo, sólo puede ser entendida en el contexto en la que sê formula, de acuerdo a un fin y a una idea que se quiere alcanzar, a una 
pregunta que se pretende responder. En el contexto de las definiciones que aquí se han examinado, todas ellas provienen del mundo vinculado a la arquitectura y el urbanismo, y datan no más allá de hace 25 años. Son el resultado de expresiones modernas vinculadas al arte, a reafirmar lo individual y lo subjetivo. Sin embargo, desde una idea más teórica respecto del paisaje, ellas responden a la base de lo expuesto en Aristóteles, la formulación de la forma que si bien requiere de la materia (realidad o cosa), puede incluso subsistir sin tenerla. Para el paisaje esto último es quizá el rol que tendría la memoria.

\section{AGRADECIMIENTOS}

Una primera versión de este ensayo fue presentado al curso: "Filosofía del Conocimiento", a cargo del profesor Luis Flores Hernández, dentro del marco del desarrollo del Doctorado en Arquitectura y Estudios Urbanos, de la Pontificia Universidad Católica de Chile, el año 2006.

\section{BIBLIOGRAFÍA}

Alpers, E. (1987). El arte de describir: arte holandés siglo XVII. Editorial Blume, Madrid, España.

Appleton, J. (1996). The experience of Landscape, Revised Edition. Editorial Wiley, UK.
Aristóteles. (1978). Acerca del Alma. Traducción de Tomás Calvo Martínez. Editorial Gredos. Madrid, España.

Cassirer, E. (1953). El problema del Conocimiento. Tomo I. Editorial Fondo de Cultura Económica. México.

Dantó, A. (2005). El abuso de la Belleza. Editorial Paidós. Buenos Aires, Argentina.

Durán, M.Á. (2007). Paisajes del cuerpo. En: La construcción social del paisaje. (Ed: Nogué J.). Biblioteca Nueva, páginas 11 - 24. Madrid, España.

Flores, L. (1998). The imagination as the origin of science. Rupture and continuity with the Quotidian lifeworld. Analecta Husserliana 52: 405-410.

Gadamer, H.G. (1957). Qué es verdad. En: verdad y Método II. (Ed: Gadamer, H.G.) Ediciones Sígueme. Salamanca, España.

Husserl, E. (1982). La idea de la fenomenología. Cinco Lecciones. Traducción de Miguel García-Baró. Editorial Fondo de Cultura Económica. México.

Maderuelo, J. (2005). El paisaje. Génesis de un concepto. ABADA Editores, Madrid, España.

Maderuelo, J. (2006). Paisaje y pensamiento ABADA Editores, Madrid, España.

Nogué, J. (2007). La construcción social del paisaje. Editorial Biblioteca Nueva, Madrid, España.

Nogué, J. (2008). El Paisaje en la cultura contemporânea. Editorial Biblioteca Nueva, Madrid, España.

Shama, S. (1995). Landscape and Memory. Editorial New York Ventage Books. New York, USA. 
Spirn, A.W. (1998). The Language of grafia. Revista de Geografia Norte Grande, Landscape, Yale University Press, New Haven and London, USA.

Tuan, Y-F. (1983). Espaco e lugar. DIFEL Tesser, C. (2000). Algunas Reflexiones sobre los significados del paisaje en geoEditorial S.A., Sao Paulo, (Trabajo original publicado en 1977). Brasil. 